\title{
Ethical and social issues in presymptomatic testing for Huntington's disease: a European Community collaborative study
}

\author{
European Community Huntington's Disease Collaborative Study Group
}

Participating centres: Institute of Medical Genetics, Cardiff, UK. D Ball

P S Harper

A Tyler

Department of Clinical Genetics, Leiden, The Netherlands. A Tibben M Vegter-van der Vlis

Centre for Human Genetics, Leuven, Belgium.

J J Cassiman

G Evers-Kiebooms

Institute of Experimental Medicine and Institute of Pyschology,

National Research

Council, Rome, Italy.

$M$ Frontali

A G Jacopini

Correspondence to Professor Peter S Harper, Institute of Medical Genetics, University Hospital of Wales, Heath Park, Cardiff CF4 4XN, UK.

Received 26 August 1993. Accepted 9 September 1993.

\begin{abstract}
An analysis of social and ethical aspects of presymptomatic testing for Huntington's disease has been carried out, based on data on linked DNA markers, from four major testing centres in different European Community countries (Belgium, Italy, Netherlands, and United Kingdom). Information was available on 603 applicants, with 213 final results given, of which $32 \%$ gave an increased risk. A series of specific issues and problems were documented systematically for all applicants, results being given on frequency of occurrence and illustrated by individual case histories. The principal issues could be grouped as problems of inappropriate referral, problems involving relatives, and problems relating to disclosure of results. At least one important problem was encountered in $46 \%$ of applicants, emphasising the importance of expert counselling, preparation, and support of applicants, and of close liaison between clinical, counselling, and laboratory staff. The extensive and detailed information available for Huntington's disease from this and other studies will be of considerable value in relation to genetic testing for other late onset genetic disorders and will be even more relevant to Huntington's disease now that specific mutation analysis is possible for this disorder.

(f Med Genet 1993;30:1028-35)
\end{abstract}

Huntington's disease (HD) is one of the most serious and frequent neurogenetic disorders of later life. The principal features include progressive motor deterioration with involuntary movements, mental involvement with dementia, and general neurodegeneration. ${ }^{1}$ Onset can be at any age, but is most commonly in adult life, with severe disability and frequently profound psychological effects on family members.

The gene for HD has recently been isolated and the underlying mutation identified as a trinucleotide (CTG) repeat sequence that is expanded in HD patients. ${ }^{2}$ The molecular genetic aspects are beginning to be explored in detail ${ }^{3-5}$ but the need for caution in applying the new information until greater experience is available has been stressed. ${ }^{67}$

The existence of close DNA markers for the HD gene for almost 10 years has allowed modification of risks of family members by analysing the pattern of linked markers in the family. ${ }^{8-10}$ Such risk alteration has now been in progress in programmes throughout the world for over seven years and a number of large series has been reported. ${ }^{11-14}$ The serious consequences of presymptomatic testing for such a serious late onset disorder have also been appreciated and documented. ${ }^{15-17}$

Although future presymptomatic testing for $\mathrm{HD}$ is likely to be based largely on mutation analysis rather than linked markers, the ethical and social issues involved will remain largely unchanged; indeed they may well become more important as the laboratory aspects are simplified.

The four centres involved in our study have all been concerned with major programmes of HD prediction in their own countries, and our combined experience has provided a considerable proportion of all such testing undertaken in Europe so far.

Some results of testing have already been reported by the individual centres, ${ }^{13141819}$ but it was considered that a combined analysis of the social and ethical aspects of testing and, in particular, the related problems encountered during testing would help to identify those issues likely to arise more generally as genetic testing becomes more widespread.

\section{Study methods}

The foundation of the present study was provided by the individual series of predictions undertaken in the four centres. No additional testing was undertaken specifically for the study. All applications for HD presymptomatic testing in each centre up to the end of 1991 were analysed, together with the results of all completed tests.

The data were extracted from the original records by the individual centre and transferred to a standard form designed for the study. All data used were anonymous and without identifying detail, this being known only to the individual centre that had performed the test. Completed forms were sent to the Cardiff centre, where data were entered onto a microcomputer for further analysis.

The core of the form consisted of (1) a sheet giving general relevant details, (2) a summary sheet of the specific problems to be analysed, (3) individual pages to record details of each specific problem, and (4) details of test result for those applicants reaching this stage.

The general data were collected on all subjects who had applied for predictive testing, 
Table 1 Principal characteristics of HD testing centres.

\begin{tabular}{|c|c|c|c|c|}
\hline & Cardiff & Leiden & Leuven & Rome \\
\hline Population & $\begin{array}{l}\text { South Wales, } \\
\text { southern England }\end{array}$ & Netherlands & $\begin{array}{l}\text { Belgium; majority } \\
\text { from Flanders }\end{array}$ & Italy \\
\hline $\begin{array}{l}\text { Contact with } \\
\text { Huntington's disease }\end{array}$ & $\begin{array}{l}\text { Longstanding and extensive in south } \\
\text { Wales; not so for southern England }\end{array}$ & Longstanding and extensive & $\begin{array}{l}\text { Longstanding and } \\
\text { extensive }\end{array}$ & $\begin{array}{l}\text { Longstanding and extensive for } \\
\text { Latium region; not for other regions }\end{array}$ \\
\hline Previous register & Yes & Yes & No & Yes \\
\hline Laboratory & $\begin{array}{l}\text { Integral. Previous molecular research } \\
\text { on HD }\end{array}$ & $\begin{array}{l}\text { Integral. Previous molecular } \\
\text { research on HD }\end{array}$ & Integral & $\begin{array}{l}\text { Integral. Previous molecular research } \\
\text { on } \mathrm{HD}\end{array}$ \\
\hline $\begin{array}{l}\text { Medical support for } \\
\text { those tested }\end{array}$ & Family doctor involved & $\begin{array}{l}\text { Family doctor not directly } \\
\text { involved. Occasional psychiatric } \\
\text { or neurological referral }\end{array}$ & $\begin{array}{l}\text { Family doctor not } \\
\text { directly involved }\end{array}$ & Family doctor not directly involved \\
\hline Payment for test & Nil & Nil & Nil & Nil \\
\hline
\end{tabular}

though the definition of an applicant varied slightly between centres. In the Cardiff series, data were recorded on all those who had made a serious enquiry about testing, though not necessarily reaching the stage of initial interview; data on this subgroup are recorded separately from those in all four centres who reached this stage of the testing procedure.

The standardised list of problems allowed each problem to be identified if it had occurred in the testing of a person. The detailed records were reviewed in order to complete this sheet and the subsequent specific sheets. Data on each problem were recorded in a way that allowed quantitative analysis, while a space was left to give an individual description of the problem; the illustrative case histories recorded later in this report are not taken from these sheets, but were supplied by the individual centres after the preliminary analysis of the data.

For the subset of applicants actually given a final test result, details of prior and final risk were recorded. This permitted a comparison of the problems arising and the composition of the series between this group and the larger number of overall applicants.

\section{Results \\ THE CHARACTERISTICS OF THE INDIVIDUAL CENTRES}

The four participating centres, three in northern and one in southern Europe, all had extensive experience in predictive testing and genetic counselling for $\mathrm{HD}$, as mentioned previously. All were based in genetics centres having a wider involvement in genetic counselling for other disorders, and all had close links with the molecular genetics laboratories involved in the HD testing, which formed part of the same institution in all centres. Table 1 summarises the principal features of the four centres.

The background to $\mathrm{HD}$ presymptomatic

Table 2 Presymptomatic testing for Huntington's disease. Applications and final results from the different centres

\begin{tabular}{lcccc}
\hline & Applicants & $\%$ male & Final results & $\%$ male \\
\hline Cardiff & $284(216)^{*}$ & 48 & 42 & 26 \\
Leiden & 183 & 41 & 127 & 43 \\
Leuven & 93 & 48 & 37 & 46 \\
Rome & 43 & 56 & 7 & 57 \\
Total & 603 & & 213 & \\
\hline
\end{tabular}

*Figure excluding those applicants not proceeding to full interview (see text). testing varied between the centres. In three (Cardiff, Leiden, and Rome), testing had developed from a programme of HD genetics research, longstanding in Cardiff and Leiden, while in Rome the establishment of the testing programme originated in the context of more recent research activity on HD. In Leuven, testing had developed from a longstanding tradition of genetic counselling for $\mathrm{HD}$ and from a long and close collaboration with the patient association.

OVERALL RESULTS OF THE SERIES

The total numbers in the different series are summarised in table 2. Data on 603 applicants were available, with 213 subjects having been given a final result. The distribution between series varied considerably, with the largest series of final results coming from Leiden, while the Cardiff series of initial applicants exceeded the others. As noted before, a proportion of these did not proceed to the first formal interview, the remainder (216 out of 284 ) giving a figure more closely in line with other centres. The great majority of applicants and those tested had an affected parent; subjects with a healthy parent but affected grandparent accounting for only 69 of 603 applicants $(11 \%)$ and 14 of 213 actually tested $(7 \%)$.

The age distribution of applicants and those tested was similar in the four centres. Only three applicants were aged under 20 , while four were over 60 , leaving the great majority of those tested $(97 \%)$ between 20 and 60 years, with a mean age of 32.7 years (male 32.2 , female 33.2) for applicants, and of 32.6 years (male 30.9 , female 33.8 ) for those given a final result.

The sex ratio of applicants (table 2) showed $47 \%$ of applicants to be male, a proportion similar to that in the general population of this age range. However, the ratio for those actually tested is lower ( $40 \%)$, though this difference is contributed mainly by the Cardiff series (26\% males).

Table 3 gives data on education levels and employment in the different series.

The distribution of final risks, where an informative result was obtained, is shown in the figure, while table 4 shows the results by centre, including uninformative outcomes, which comprised $11 \%$ of the total.

The proportion of informative results giving a raised risk is $32 \%$, a value comparable to that 
Table 3 Educational levels and employment in the different series.

\begin{tabular}{|c|c|c|c|c|c|}
\hline \multicolumn{6}{|c|}{ Educational levels } \\
\hline & Pre-school & Less than high school & High school plus & Degree & $\mathbf{N} / \mathbf{K}$ \\
\hline $\begin{array}{l}\text { Cardiff } \\
\text { Leiden } \\
\text { Leuven } \\
\text { Rome }\end{array}$ & $\begin{array}{c}11\left(9^{*}\right) \\
0 \\
0 \\
0\end{array}$ & $\begin{array}{c}151\left(140^{*}\right) \\
89 \\
31 \\
22\end{array}$ & $\begin{array}{l}48\left(42^{*}\right) \\
81 \\
37 \\
14\end{array}$ & $\begin{array}{l}23\left(21^{*}\right) \\
9 \\
9 \\
7\end{array}$ & $\begin{array}{c}51\left(0^{*}\right) \\
2 \\
16 \\
0\end{array}$ \\
\hline \multicolumn{6}{|c|}{ Employment } \\
\hline & Manual & Non-manual & $\mathrm{N} / \mathrm{K}$ & Total & \\
\hline $\begin{array}{l}\text { Cardiff } \\
\text { Leiden } \\
\text { Leuven } \\
\text { Rome }\end{array}$ & $\begin{array}{l}147\left(123^{*}\right) \\
104 \\
36 \\
22\end{array}$ & $\begin{array}{l}99\left(88^{*}\right) \\
76 \\
36 \\
21\end{array}$ & $\begin{array}{l}38\left(6^{*}\right) \\
1 \\
21 \\
0\end{array}$ & $\begin{array}{l}284\left(217^{*}\right) \\
181 \\
93 \\
43\end{array}$ & \\
\hline
\end{tabular}

*Represents group (216) which received counselling.

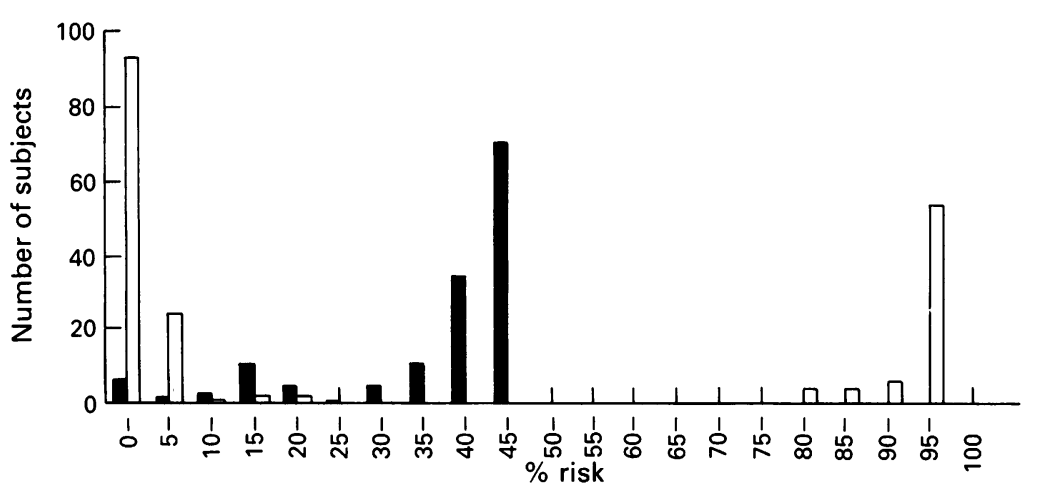

Pre-test $\square$ Post-test

Age adjusted risk before and after testing.

Table 4 Risk alteration after presymptomatic testing (see figure for detailed risk distribution).

\begin{tabular}{|c|c|c|c|c|c|c|}
\hline & \multicolumn{2}{|c|}{ Risk raised } & \multicolumn{2}{|c|}{ Risk lowered } & \multicolumn{2}{|c|}{ Uninformative } \\
\hline & No & $\%$ & No & $\%$ & No & $\%$ \\
\hline $\begin{array}{l}\text { Cardiff } \\
\text { Leiden } \\
\text { Leuven } \\
\text { Rome }\end{array}$ & $\begin{array}{r}12 \\
45 \\
10 \\
1\end{array}$ & $\begin{array}{l}29 \\
35 \\
27 \\
14\end{array}$ & $\begin{array}{r}25 \\
74 \\
18 \\
5\end{array}$ & $\begin{array}{l}60 \\
58 \\
49 \\
71\end{array}$ & $\begin{array}{l}5 \\
8 \\
9 \\
1\end{array}$ & $\begin{array}{r}12 \\
6 \\
24 \\
14\end{array}$ \\
\hline Total & 68 & 32 & 122 & 57 & 23 & 11 \\
\hline
\end{tabular}

Table 5 Specific problems encountered in HD presymptomatic testing.

\begin{tabular}{lrrrrr}
\hline & Cardiff & Leiden & Leuven & Rome & Total \\
\hline $\begin{array}{l}\text { Problems of referral } \\
\text { Referral without permission }\end{array}$ & $6(3)$ & 0 & 3 & 0 & 9 \\
Referral of minor & $29(23)$ & 0 & 5 & 3 & 37 \\
Referral under third party pressure & $11(11)$ & 5 & 6 & 2 & 24 \\
$\begin{array}{l}\text { Problems involving relatives } \\
\text { Threat to privacy of information }\end{array}$ & $27(23)$ & 1 & 0 & 1 & 29 \\
Refusal to supply blood sample & $16(15)$ & 10 & 4 & 1 & 31 \\
Use of stored research sample & $1(1)$ & 4 & 7 & 0 & 12 \\
Unsolicited risk alteration & $2(1)$ & 4 & 0 & 1 & 7 \\
$\begin{array}{l}\text { Problems of disclosure } \\
\text { Disclosure to physician refused }\end{array}$ & $3(3)$ & 4 & 0 & 0 & 7 \\
Disclosure to relative/spouse refused & $2(2)$ & 11 & 1 & 0 & 14 \\
Request for disclosure by relative & $0(0)$ & 0 & 0 & 0 & 0 \\
Request for disclosure by third party & $10(5)$ & 0 & 2 & 0 & 12 \\
Request for disclosure to self & $1(1)$ & 11 & 0 & 1 & 13 \\
Non-compliance with protocol & $20(11)$ & 4 & 5 & 8 & 37 \\
Other problem & $20(17)$ & 18 & 9 & 1 & 48 \\
\hline
\end{tabular}

() indicated date restricted to applicants proceeding to full interview in Cardiff series. of other reported series; the basis of this difference from the $50 \%$ and $25 \%$ prior risk is at least in part related to the age of applicants. It can be clearly seen from the figure that the age adjusted risk of many subjects is considerably less than their prior risk, having already passed through a significant portion of their risk period.

A significant proportion of those requesting testing were unable to be given a final result. The most frequent reason (57 cases) was an inadequate family structure, with key family members dead or unavailable for testing. However, difficulties in confirming the diagnosis of HD were also prominent (31 cases), while no fewer than 47 applicants proved already to be clinically affected.

\section{ANALYSIS OF PROBLEMS}

The proportion of applicants in whom at least one important problem arose was high, $46 \%$ (280 out of 603 ). The specific problems on which data were collected on individual sheets are listed in table 5. Those encountered in the Cardiff series are subdivided according to whether they were encountered in the series of preliminary enquiries, since this category was absent in the other centres, but analyses are based on the whole series. Details on each problem are given below, with specific case examples where relevant. Three principal groups of problems could be identified: the first relates to referrals or applications that might be considered inappropriate; the second to the requirement for involving other family members in the testing process; while the third involves issues of disclosure and confidentiality.

\section{Problems of referral}

REFERRAL WITHOUT PERMISSION

This indicated that an applicant had been referred without that person being aware of this, or without having given permission for testing. Of the nine instances, five were referred from psychiatrists.

\section{Example (Cardiff)}

A psychiatrist referred a 50 year old man for testing. He had been under his care for many years, suffering from severe depression, but had never showed any neurological signs. It was suspected that the depression was related to the family history of HD. The psychiatrist asked for the patient to be tested without his knowledge and offered to send a blood sample. $\mathrm{He}$ also asked the genetic centre to send the result to him so that he could decide whether or not to inform his patient. The genetic centre explained why this was not possible and obtained permission to see the patient, who was quite uninterested in testing; therefore, it was not carried out. (This case also illustrates a request for information from a third party.)

\section{REFERRAL OF A MINOR}

This was defined as any referral under 18 years of age (the usual age of majority in the coun- 
tries concerned). The mean age of such children was $10 \cdot 5$ years, and the source of referral was most commonly parents (23 cases) but also social workers, mainly from adoption agencies (7 cases), as well as other professionals (table 6). It can be seen that the majority of the 39 cases came from the Cardiff series; it is possible that comparable referrals to the other centres may have been filtered out at an early stage.

\section{Example 1 (Leuven)}

A 45 year old mother whose husband had committed suicide requesting testing for her 14 year old daughter. At the time her husband committed suicide, they were divorced. The mother was only recently informed about the nature of the diagnosis of HD in her father in law (she had had no contact with her husband's parents for the last eight years).

Thereafter, she started to have doubts whether her husband might have committed suicide in association with the onset of HD. Her daughter had no contact at all with her affected grandfather. According to the mother, the girl was not aware of the presence of any serious disease in her grandfather or of the suicide of her father.

This woman was furious and indignant about our refusal to test her 14 year old daughter. She was convinced that it was her right to know her daughter's status. However, she was only considering the possibility of a favourable result and did not want to think about the consequences of an unfavourable result in her daughter. It was very difficult for the mother to accept that a predictive test should only be performed if the at risk person can make an informed decision and that testing is never performed below 18 years. Follow up counselling was offered.

\section{Example 2 (Cardiff)}

A social worker from an adoption agency asked for a baby to be tested. The child's mother, aged 19 years, was at $50 \%$ risk and there was some concern that her erratic life style and promiscuous behaviour might herald the onset of HD. The child's father was unknown. The baby was said to be the result of a brief encounter and the mother had no interest in the child. The adoption agency felt that the prospective adoptive parents had the right to know whether the baby was likely to be a gene carrier. Counselling was accepted by the social worker, the adoptive parents, and the mother, who was totally opposed to being tested herself. However, she was prepared to consider voluntary surveillance so that, if she were to

Table 6 Referral of minors.

\begin{tabular}{lccccc}
\hline Referral source & Cardiff & Leiden & Leuven & Rome & Total \\
\hline Parents & 16 & 0 & 4 & 3 & 23 \\
Professionals* & 10 & 0 & 1 & 0 & 11 \\
Self & 3 & 2 & 0 & 0 & 5 \\
Total & 29 & 2 & 5 & 3 & 39 \\
\hline
\end{tabular}

*Social worker 7 , psychiatrist/paediatrician 4. develop symptoms, the adoptive parents could be told.

In fact, owing to the poor family structure, the chance of obtaining an informative test result was low, but the situation could have created great difficulties had a specific mutational test been available.

\section{REFERRAL UNDER THIRD PARTY PRESSURE}

This indicated that testing had been sought, not primarily by the person to be tested, but by another person, though with permission. Subjects involved were family members (most commonly spouse or partner) in 16 cases, professionals in eight cases.

\section{Example 1 (Leuven)}

A young woman was living with her partner who is at risk for Huntington's disease. Initially, she completely denied the fact that her partner had a $50 \%$ risk of becoming affected. When her parents became aware of this risk, they had very strong objections to the relationship.

As a consequence of her own mixed feelings, in combination with the parental objections, she could not cope any longer with the at risk status of her friend and became depressed. Under the influence of her parents, she considered that predictive testing could offer a way out of this situation. During the initial session in the genetic centre, it was clear that the young man who was at risk was not at all motivated to have a predictive test. Because of the relationship problems, associated partially with the risk for Huntington's disease, and because of the depression of the partner, the couple was immediately referred to the psychiatrist of the team for a number of therapeutic sessions.

\section{Example 2 (Rome)}

A 31 year old woman at $50 \%$ risk came to our centre in 1987 for genetic counselling. At that time, presymptomatic testing was not yet available in Italy and DNA banking was proposed of samples from her affected father and uncle, which was accepted. In 1991, she asked for presymptomatic testing and came to the first session accompanied by her fiancé. After the introductory part, the psychologist asked to speak individually to the applicant. When asked why she decided to be tested, she said that she could not see how to escape the test, since she had been engaged to her fiancé for 10 years. Both were living in a small village where everyone knew everything about everybody and the disease in her relatives was well known to the fiance's family; in addition, his sister was a medical doctor and had a professional knowledge of the disease. After initial opposition to the engagement, owing mainly to the lower social class of her family, the fiancé's relatives accepted her and she had a good relationship with them. However, when they learned that a presymptomatic HD test was available, they 
became violently opposed to their marriage unless a presymptomatic test was done.

The applicant thought that she had no choice, although knowledge of her genetic status was not relevant for her. Her religious beliefs led her to accept everything that can happen in life, and the disease was not worse than other possible events. However, having been engaged for such a long time, she could not break the engagement: "the gossip would be awful and my mother would die of it". In addition, she felt very deceived by her fiancés inability to oppose his family situation.

During the lengthy session with the psychologist, the applicant realised that she did not want to submit to the test, not because of fear of a 'bad' result, but because she could not accept the test as a condition for marriage after such a long engagement. Contact with the psychologist was kept by the applicant, during which her level of self-esteem increased. Some months later, she announced that she was going to marry her fiancé, not knowing, however, what made his family withdraw their opposition. She intended to undergo testing after marriage without telling the husband. When the psychologist made her think about the difficulty of hiding the emotional impact of a result, either positive or negative, she asked for more time to decide.

This case exemplifies: (1) how availability of a test can induce social pressure on at risk subjects to undertake it; (2) the necessity of long and patient psychological work to unravel deep attitudes towards the test and towards the environment that stimulated its request, in order to protect a subject's right to an autonomous decision; (3) how the decision process can be long and time consuming both for the subject and the genetic counselling team; (4) how the whole procedure, for the above reasons, is not easily transferable from research centres to a routine National Health Service setting.

Although most examples of third party pressure have related to family members, we have also encountered pressure from professionals; in some cases, the distinction from the previously discussed situation of 'referral without consent' is a fine one.

\section{Problems relating to other family members}

One of the principal limitations of genetic prediction based on closely linked genetic markers is that a result depends on the analysis of the genetic pattern in a family, not on the genotype of the applicant alone. This can result in a variety of difficulties, including those outlined below.

\section{THREAT TO PRIVACY OF INFORMATION}

To undergo presymptomatic testing for a person, it is essential to have accurate diagnostic information on those who are affected, and to be certain whether a subject whose sample is being used is affected or clinically normal. In a number of instances, relatives were reported as affected by the family, but had never been formally diagnosed; in some cases, they were unaware of their condition and had avoided medical contact. Others were noted as having shown equivocal features. In such instances, the use of information would involve not only providing a sample, but the establishing of a diagnostic situation which had not been sought by the subject, and which would result in invasion of privacy. We avoided the use of samples in such situations.

\section{Example (Cardiff)}

A 35 year old woman was distressed to receive what she described as a 'peremptory' request from her sister, living in another part of the UK, for a blood sample. The woman had applied for testing and had, apparently, been asked by her local genetic centre to obtain this sample. Her sister was worried and very depressed about marital problems and vague non-specific symptoms which, she felt, could herald the onset of HD. She had firmly decided not to be tested as she felt that an adverse result could cause her to become suicidal. She was reassured that she did not need to provide a blood sample and was offered support, if needed, in any further communications with her sister.

\section{REFUSAL TO PROVIDE A SAMPLE}

The trauma and disruption often produced by the occurrence of HD in a family may be reflected in strained family relationships which, in turn, may result in a family member, necessary to provide a risk estimate for the applicant, refusing to cooperate. While sensitive discussion and explanation will resolve most such cases, a substantial number of remaining problems were encountered in this study.

\section{Example 1 (Cardiff)}

A not at risk parent of an applicant refused to give a blood sample to enable three of her adult children to be tested. She felt that her children had neglected her for many years and that she was under no obligation to them. She had divorced their father many years ago, before he had developed HD, and subsequently had had no contact with him. The family, therefore, had divided loyalties. Eventually, after family counselling sessions, relationships were resumed and the mother gave a blood sample.

\section{Example 2 (Leuven)}

A mother with early symptoms of Huntington's disease could not cope with the psychological problems associated with the onset of the disease. In this context, she was not yet prepared to have the diagnosis confirmed by a neurologist and she refused to supply a blood sample to allow testing of her two adult children who entered the test programme. The main reason given was that she could not cope 
with the implications of the test request by her children in this particularly difficult period.

\section{USE OF RESEARCH SAMPLES}

Many centres involved in HD presymptomatic testing, including the four in this study, have been involved in previous molecular research and have maintained stores of DNA on HD kindreds, whose members may later request testing as a service. The use of such samples, especially from subjects at risk, may be contentious unless it is completely clear what those sampled have consented to.

While the use of samples from dead subjects may be vital in allowing prediction, we have generally avoided the use of research samples whenever possible. In Leuven, research samples were only used when dead patients were vital in allowing prediction and in agreement with the family. Moreover, this decision was made at the time of DNA storage.

\section{Problems of disclosure and confidentiality}

DISCLOSURE TO PHYSICIAN

Information on a person's risk status regarding $\mathrm{HD}$ is a matter of the greatest sensitivity and personal importance, with implications for insurance, employment, and marriage among others. All centres undertaking presymptomatic testing have found that an assurance of total confidentiality is given the highest priority by applicants, and the framework of testing is constructed accordingly in terms of both the actual result and the associated counselling.

The practice in the four centres differed considerably on this point, one of the few areas where major differences existed. In Leuven and Rome, the majority of applications came directly from the subject at risk, as noted earlier, not involving any medical professional. In Leuven, results were given face to face with no written result that could be sent either to the applicant or to anyone else. Upon request of the applicant, a telephone call with the applicant's physician was made in a number of cases. In Rome, written results were given to the applicant in the same session as they were communicated verbally. In the Cardiff series, referrals were channelled through a professional, usually a clinical geneticist, while the result, initially given face to face, was confirmed to the applicant in writing, and also to the applicant's family doctor, and referring clinician, if permission for this was granted. In Leiden also, the family doctor was usually involved at the referral stage and afterwards with the permission of the applicant; seven applicants from Cardiff and Leiden were unwilling for disclosure to occur.

\section{REFUSAL OF DISCLOSURE BY THE APPLICANT TO} FAMILY MEMBERS

This was encountered in 14 instances, principally involving spouses and children; such sharing of risk information was recommended in the counselling protocols of all the centres, but if a subject was insistent in not sharing the result or the fact of being tested, this was not regarded as a reason against testing.

It is interesting to note that no direct application from a relative to have access to a test result was received, even though this was an item specifically enquired for on the questionnaire. The consequences of non-disclosure or misleading information on family members can be seen from the following examples.

\section{Example 1 (Leiden)}

A 48 year old man with three children entered the presymptomatic testing programme, but did not respond to the invitation to receive the test result. Although he has still not been given the results, he has informed his children and other relatives that his test was normal.

Example 2 (Leiden)

A 25 year old woman, at $25 \%$ prior risk, applied for testing and found that her mother (at $50 \%$ prior risk) was willing to cooperate and wished to learn her own result. Both women had a high risk result and were informed of this separately. Subsequently, the daughter told her mother and sibs that she had received her result in a sealed envelope and pretended that she did not wish to know the result until a later, more appropriate time (when considering having a family).

\section{Non-compliance with protocol}

The final items listed, non-compliance with the protocol and 'other problems', contained (not surprisingly) a variety of problems relating to attendance at counselling and follow up interviews, participation in neurological and psychological evaluations, and other aspects. Considering the stressful nature of HD presymptomatic testing and the expense and inconvenience of travel often involved, it is perhaps surprising that the number is not greater.

\section{Testing subjects at $25 \%$ prior risk}

The great majority of subjects in this study had a parent affected with HD, only $11 \%$ of applicants and $7 \%$ of those tested being second degree relatives, with a prior risk of $25 \%$. Although, in some cases, the intervening parent had died of an unrelated cause, the situation where a living parent exists, whose child requests testing, creates a particularly difficult situation, likely to be encountered more frequently now that testing for a specific mutation is possible.

Two principal types of situation were encountered in the study. (1) A parent at risk does not wish to know their genotype, while their child requests a presymptomatic test. The child's status, if affected, will reveal that of the at risk parent. (2) A more distant relative has agreed to give a blood sample to help a relative and, as a result of family genotyping, their own risk may be increased. In situation 2, it is often possible to do a presymptomatic test 
for the applicant, while avoiding sampling the relative; in situation 1 , only exclusion testing will ensure the parent's right 'not to know'.

\section{Example 1 (Rome)}

A 24 year old man with an affected paternal grandfather and an at risk father asked for a presymptomatic test. The team asked to speak to the father in order to clarify the fact that a raised risk for the son would increase his own risk and ask him whether he would wish to know his own status. The father was not willing to know, although he understood his son's motives in asking for the test and was willing to cooperate with a blood sample. The team decided that, in order to protect the father's right not to know, only exclusion testing could be offered to the son.

\section{Example 2 (Cardiff)}

A man at $25 \%$ risk of $\mathrm{HD}$ asked for exclusion testing as his father, at $50 \%$ prior risk, did not wish in the first instance to be tested himself. They came from a large pedigree and it would have been easy to alter the father's risk inadvertently by full genotyping of other family members. This was avoided by deliberately not typing an affected sib of the father so that phase remained unknown, thus leaving the father's risk unaltered, while giving the possibility of either a very low risk for the son or of raising his risk to that of the father's present level. Careful forethought and discussion with the family and with the laboratory was needed for this approach to be achieved successfully.

\section{Discussion}

Our study, along with the individual programmes on which it is based, has shown that presymptomatic testing for HD has been carried out effectively in four different European countries, using broadly similar protocols for the preparation, counselling, and support of those undergoing testing. However, the number and variety of significant problems that have been encountered, despite the absence of major adverse effects, raises major doubts as to whether testing without an established protocol and the availability of experienced staff is advisable. This will become an important issue now that simpler and probably cheaper mutational testing, without the need for sampling other family members, is possible.

The specific problems here are not unique to $\mathrm{HD}$, but represent items that could arise in the context of testing for many late onset, progressive genetic disorders. Those relating to referral and consent are of special relevance and illustrate the importance of the testing process being a joint clinical and laboratory activity. An isolated laboratory that analysed without question all samples referred to it could have created serious ethical dilemmas by the testing of minors or of subjects who had not given consent.

The group of problems involving the sam- pling of family members is also highly relevant to testing in other disorders based on genetic linkage. Not only does the linkage approach reduce the accuracy of prediction owing to recombination between marker and disease, but many applicants have a pedigree structure that makes linkage based testing impossible, with key family members dead or unavailable. Most of such subjects would not have entered the current series. The problems discussed in this group raise difficult ethical issues, whose answers may not be clear cut; thus whether or not to use a stored research sample, or to approach a family member suspected of being affected, will require careful individual decisions. However, unless the general principles and the possibility of problems arising are appreciated, serious difficulties could be created for both the testing centre and the subjects concerned.

The third group of problems, concerned with confidentiality and disclosure, illustrate the importance not only of scrupulous attention to confidentiality of laboratory and clinical records, but also of a clear policy as to how test results will be handled. All four centres had a policy of giving results face to face, never by letter or telephone; the policy of one centre (Leuven) not to generate a written result avoids the possibility of accidental disclosure. The theoretical risk in this centre of later misinterpretation or forgetfulness by those given the result verbally was considered to be minimal for two reasons. First the applicant was always accompanied during the communication of the test result. Secondly, the test result was discussed again during at least two post-test counselling sessions. The question of third party access to results by bodies, such as insurance agencies, is an area of considerable concern. There is no doubt that, in the UK at least, insurance companies expect to have access to such results and consider genetic test information as no different from other medical test results. ${ }^{20}$

The rapid pace of advances in mapping and isolating disease genes means that already the possibility of prediction now exists for numerous other important disorders of late onset; inherited prion dementias, adult polycystic kidney disease, and the familial cancer syndromes are examples where this is already available.

For some of these conditions, specific mutation testing is a possibility, while for others linkage based analysis is required, but for all of them, whether involving the nervous system or not, the problems outlined in this paper are of relevance.

Now that a specific mutation has been identified for $\mathrm{HD},{ }^{2}$ with the great majority of cases studied so far showing a clear expansion of the unstable CTG repeat in the HD gene, it is likely that this will rapidly supersede the use of linked genetic markers. Some of the ethical and practical problems encountered in this study will be reduced by the use of mutation analysis; thus privacy should be enhanced by samples from multiple family members no longer being needed. Other problems may be 
increased; in particular, the specificity and relative ease of mutation testing may result in it being requested by clinicians without proper information and counselling being given to the subject, or even without consent. Requests from those at $25 \%$ risk, rare in the present series, are likely to become more frequent; by no longer requiring the direct involvement of the intervening parent, serious conflicts between right to privacy and right to know of the subjects concerned could arise.

We consider it essential that the ethical and social aspects of HD presymptomatic testing continue to be monitored closely, and for problems as well as benefits arising from use of mutation analysis to be compared with previous forms of testing. We hope that the information from this study, summarising the experience of four European centres with major involvement of presymptomatic testing, will be of value in ensuring that this is carried out to the highest possible standard, not only for those at risk for HD, but for other genetic disorders of late onset.

We thank our laboratory colleagues in the four centres who were responsible for undertaking the molecular analyses and without whose interest and close collaboration this study would not have been possible. We are grateful also to all our colleagues involved in the preand post-test counselling. The study was funded by an award from the European Community programme on the ethical and social aspects of human genome research.

1 Harper PS. Huntington's disease. London: Saunders, 1991 2 The Huntington's Disease Collaborative Research Group. A novel gene containing a trinucleotide repeat that is expanded and unstable on Huntington's disease chromosomes. Cell 1993;72:971-83.

3 Duyao M, Ambrose C, Myers R, et al. Trinucleotide repeat length instability and age of onset in Huntington's disease. Nature Genet 1993;4:387-92.

4 Snell RG, MacMillan JC, Cheadle JP, et al. Relationship between trinucleotide repeat expansion and phenotypic variation in Huntington's disease. Nature Genet variation in
$1993 ; 4: 393-7$

5 Andrew SE, Goldberg YP, Kremer B, et al. The relationship between trinucleotide (CAG) repeat length and clinical features of Huntington's disease. Nature Genet 1993;4:398-403.

6 Harding AE. The gene for Huntington's disease. $B M F$ 1993;307:396-7.

7 Harper PS. Clinical consequences of isolating the gene for Huntington's disease. BMF 1993;307:397-8.

8 Meissen GJ, Myers RH, Mastromauro CA, et al. Predictive testing for Huntington's disease with use of a linked DNA marker. N Engl f Med 1988;318:535-42.

9 Hayden MR, Robbins C, Allard D, et al. Improved predictive testing for Huntington disease by using three linked DNA markers. Am 7 Hum Genet 1988;43:689-94.

10 Brandt J, Quaid K, Folstein SE, et al. Presymptomatic diagnosis of delayed-onset disease with linked DNA diagnosis of delayed-onset disease with linked DNA markers: the experien

11 Craufurd D, Dodge A, Kerzin-Storrar L, et al. Uptake of presymptomatic predictive testing for Huntington's disease. Lancet 1989;ii:603-5.

12 Brock DH, Mennie M, Curtis A, et al. Predictive testing for Huntington's disease with linked DNA markers. Lancet 1989;ii:463-6.

13 Tyler A, Morris M, Lazarou L, Meredith L, Myring J Harper P. Presymptomatic testing for Huntington's disease in Wales 1987-90. Br $\mathcal{F}$ Psychiatry 1992;161:481-8.

14 Tibben A, Vegter-vd Vlis M, Skraastad MI, et al. Presymp tomatic DNA testing for Huntington disease in the Netherlands. Birth Defects 1992;28(1):127-31.

15 Morris M, Tyler A, Lazarou L, Meredith L, Harper PS Problems in genetic prediction for Huntington's disease. Problems in genetic p
Lancet 1989;ii: $601-3$.

16 World Federation of Neurology Research Group on Huntington's Disease. Ethical issues policy statement on Huntington's disease molecular genetics predictive test. $\mathcal{f} \mathrm{Med}$ Genet 1990;27:34-8.

17 Bloch M, Hayden MR. Predictive testing for Huntington's disease in childhood: challenges and implications. $\mathrm{Am} \mathcal{F}$ Hum Genet 1990;46:1-4.

18 Demyttenaere K, Evers-Kiebooms G, Decruyenaere $M$ Pitfalls in counseling for predictive testing in Huntington disease. Birth Defects 1992;28(1):105-11.

19 Jacopini GA, D'Amica R, Frontali M, Vivona G. Attitudes of persons at risk and their partners towards predictive testing. Birth Defects 1992;28(1):113-17.

20 Harper PS. Insurance and genetic testing. Lancet 1993;341:224-7. 